\title{
Key Role of the Diagnosis in Patients Suffering from Dementia
}

\author{
Amalia C Bruni ${ }^{1 *}$, Valentina Laganà ${ }^{1}$, Natalia Altomari ${ }^{1,2}$, Patrizia Notaro ${ }^{1,2}$ and Francesca Frangipane ${ }^{1}$ \\ ${ }^{1}$ Regional Neurogenetic Centre Azienda sanitaria Provinciale Catanzaro, Italy \\ ${ }^{2}$ Department of Biology, Ecology and earth Science, Italy
}

Submission: July 26, 2017; Published: July 27, 2017

*Corresponding author: Amalia C Bruni, Regional Neurogenetic Centre Azienda sanitaria Provinciale Catanzaro, Italy,

Email: amaliaceciliabruni@gmail.com

\begin{abstract}
The current number of people suffering from dementia is about 35.6 million and this number is destined to seriously growth. Dementia is mostly unknown and its in-vivo diagnosis frequently remains in the field of the uncertainty and probability. An early comprehension of the disease is crucial because it determines its impact on the person and on the family. The present opinion started from the analysis of the letter written by Robin Williams' wife about his illness (the Lewy Body Dementia) before, during and after death. Several issues arouse from the commentary and deal with the difficulties involved in the diagnosis; the role of cognitive reserve and the pitfalls growing in the couple, the lack of information, the awareness of the disease; the theme of the suicide linked to dementia and the role of neuropathology. All of these themes need a reflection and must be transformed into new attitudes towards dementias. The hope of Susan, and of many family members, is that the suffering of their relatives may one day help other patients, other families and doctors and researchers to fight these terrible diseases. With them and for them we will not surrender.
\end{abstract}

Keywords: Dementia; Lewy body dementia; Diagnosis; Behavioral disorders; Robin williams

\section{Introduction}

Despite the great evolution and progression in research, dementia is still today an obscure and complex disease. Its intricate network of signs and symptoms constitutes a complicate path, difficult to understand for everyone involved: the patient, the family, the medical team. An early comprehension of the disease is crucial because it determines its impact on the person and on the family. Nowadays, to deal with dementia means to face an enemy who shows his name, face and weapons only when little or nothing can still be done. Many obstacles however to an early diagnosis are often ingrained just because of the nature of dementia. There is the person capable, more or less, consciously or not, to hide the symptoms and the first cognitive gaps. There is the resistance of family in front of unusual behaviors and a more common refusal and shame in front of the illness. There are vague symptoms, such as depression or anxiety, which not immediately, and perhaps not later, are linked to some neurodegeneration process. There is the probable diagnosis. There is a lack of support for caregivers, which are those who care for all the time. There is the neuropathology brought into play only at the end of this entire story. In 2014, the actor Robin Williams suicided in his house, his wife Susan has never accepted the word depression, which was immediately related to the extreme act of Robin. She argued that it was something more, something which was devastating his brain, a disease that she called the terrorist. In 2016, she wrote an editorial on neurology [1] to talk about what happened inside and outside the brain of his husband. It could have been the story of one of the many movies that Robin starred. Susan wrote a piece of poetry, but the aim was not writing to make a movie or a play, the aim was different. This was a prayer. Susan wrote to us, doctors and researchers, hoping to be able to understand again, even after all this time what happened, for what reason and to figure out if she could have helped him more or better. She pushed us to work, to move forward, not to give up despite failures and still to release ourselves from a deep sorrow, which consumes.

There are many Susan in the world who are unable to communicate, in such affective way, about this pain and try to get rid. Susan is all the families, all the caregivers who, next to their beloved, live similar stories, similar efforts, sometimes even worse as when, for example, there is an awareness of a genetic mutation and when, your loved one is 35-40 years-old and you have little children who do not understand why their daddy wants to play with their toys, why he gets angry and beats them if they steal the Legos or toy car. The editorial, beyond the 
emotions and feelings, is also an important educational piece which underlines some fundamental points about the complex issues generated by dementia. We can and must make some reflections on it and understand both strong and weak points of who suffer, who cares and who cures.

\section{The difficulty of diagnosis}

This is the big problem: today only $50 \%$ of patients with any kind of dementia receives diagnosis [2]. The others are ghosts, hidden in their houses or in nursing homes, unidentified or sweetened under shameful, non-specific, terminologies. Despite efforts in fighting the definition of "senile dementia" still today we hear and read about it. Of course, it has been profusely said, the aging phenomenon does not necessarily match with a behavioral and cognitive decline. The fact that this is, unfortunately, frequent is not necessary a physiologic consequence, it would be like saying that, during a varicella epidemic, to have the varicella is normal just because everybody has it. On the other side of the life curve there is the young patient: the one that, just because of his early age, could not suffer from dementia, the one that, because of a preeminent behavioral disorder, is relegated in the often-indistinguishable ravine of psychiatric diseases. How many diagnosis of schizophrenia in the presence of FTLD $[3,4]$. When symptoms invade behavior and mind they seem to sidetrack the doctor: it is not easy to recognize unspecific symptoms, such as depression or anxiety, as a possible sign of an incoming dementing disease. Although in the evaluation of a memory disorder there are neuropsychological tests, as the Free and Cued Selective Reminding Test (FRCST) [5,6], which address to the different forms of dementia, unfortunately this is not the case of behavioral disorders and more generally of mind disorders. The idea that the mind is separate from the brain is still rooted, although the existing criteria describing various types of dementia, Alzheimer's Disease [7], frontotemporal dementia [8] or as in this case, dementia with Lewy bodies [9], accurately depict symptoms and signs. And yet, how many patients come at such advanced stage that doctors cannot identify which path the disease has followed before spreading throughout the brain. One of the more important problems is the reconstruction of patient's personal history from its family that difficultly tends to recall sad and painful episodes and, frequently, doesnot remember the timing sequence of symptoms. Still it is precisely the sequence of a series of symptoms. Still it is precisely the sequence of a series of symptoms and signs that allow us to have the Gestalt of the disease and thus to assume a probable diagnosis. Family members, however, do not know what to look out for and the weight to give to apparently trivial situations. Preliminary data [10] from a research on a set of about two thousand patients with Alzheimer's disease have shown the presence of behavioral disorders, also genderdifferent, even before the onset of the disease, in agreement with other literature reports [11]. But this is not enough. We should cross sensitivity and specificity measures sifting to define a peculiar behavior as a clinical biomarker. Nevertheless we know it for sure, thanks to the studies of genetic mutations carrier subjects (DIAN and GENFI) respectively in Alzheimer's disease and Frontotemporal dementia, that neurodegenerative diseases and their pathological proteins counterparts, begin to wallow in our brains from 15 to 10 years before the onset of symptoms $[12,13]$. But what value of "risk" can we give to our boomer's anxiety or post retirement depression? Much must still be done in terms of study and research in this direction, and much more needs to be built in sense of dissemination of knowledge in the whole community, not just the medical one. Dementia with Lewy bodies is a treacherous disease, perhaps even worse than Alzheimer's disease, but at least as the frontotemporal dementia. The behavioral signs and, above all, the fluctuations of the clinical course are so unlikely in DLB that family members frequently tell us that the patient "looks like he is acting intentionally". We know that the DLB has a variable prevalence between 0.3 and $24.4 \%$ in the studies [14], and these so widely variable data explain the difficulty of investigation and diagnosis. The disease is clinically characterized by a progressive cognitive decline, often hallucinations and delusions, parkinsonism and a floating attention. However, the criteria which permitted to distinguish the disease from the great syndromic cauldron of dementias, are poorly specific and not perfectly able to differentiate the overlapping forms with Alzheimer's disease, although the high prevalence of hallucinations delusions, anhedonia, anxiety and apathy that occur at the DLBonset seem to be very indicative [15]. Patients with DLB usually manifest at onset very mild cognitive impairment within a framework of psychotic subacute state, predominantly characterized by hallucinations and delusions [9].

Hallucinations are predominantly visual, detailed, often nocturnal, recurrent and almost constant during the course of the disease. Less frequently, patients also have auditory hallucinations and paranoid delusions. Often, depressive and anxious symptoms and behavioral disturbances associated with REM sleep (RBD) are frequently observed and they manifest as vivid and terrifying dreams associated with simple or complex motor behaviors seriously disturbing the bed partners. Less frequently, in the early stages, it may be present a rigid-akinetic extrapyramidal syndrome -no tremor-usually symmetrical, partially sensitive to dopaminergic therapy. Memory skills are relatively preserved, while attention is impaired together with visual-spatial disorders and difficulties in critic and judgment. Cognitive performances are highly fluctuating and they may occur with extreme variability (minutes or hours) over the same day. Despite Robin Williams lived in the US, the MECCA of the criteria and advanced medicine, he did not receive the diagnosis, neither early nor timely. The presence of depression, anxiety, the apparently hypochondriacs signs, tremor and the reduction of smell (typically parkinsonian latter) together with the sensitivity to antipsychotics (which worsen the clinical picture and is an important sign to suspect the disease) have not been 
pigeonholed temporally in the right direction and evaluated as pieces of a single puzzle that was in building.

\section{Cognitive reserve}

Robin Williams' story testifies how the onset of cognitive symptoms of a dementia disease can be postponed over time and altered by events and life experiences. The cognitive reserve model [16] tries to explain the discrepancy between brain damage and its function. High level of education, learning, skills and knowledge acquired during the whole life could explain the possibility for some individuals to resist as long as the neurodegeneration occurs, showing, at the beginning of the disease, only mild symptoms. In particular, and this is the case of Robin, an actor accustomed to exercise and strain memory, cognitive activity during adulthood could have an even more important role in the construction of this reserve [17]. In front of an atypical onset of the disease, this of course can put people and doctors off track, making difficult the choice for a diagnostic label.

\section{The couple and the disease}

A disruptive event such as a dementia not only affects the person but also "infects" emotionally whoever is around [18]. Both in a long-standing relationship and in a relatively recent love story, who joins the affected person takes the role of the "stronger": Susan takes care of Robin, she helps and supports him, supervising him and his symptoms. She gets stronger to brave one of the most difficult and intense moments in a relationship that paradoxically seems to strengthen thanks to the sharing of the disease. She is indulgent towards Robin's aggressive behavior, his fears and discomfort, his concern and his pleas for help. The role of the family caregiver in the containment of the disease is fundamental: an empathic environment is able for an adequate managing of behavioral disorders, and also to understand and analyze symptoms [19]. The acceptance of the disease is the difficult task for caregivers because they need to decode inexplicable attitudes, analyze behaviors and also discover the loved "nothing else or not different" from what he/she was before, but just different for the inability to express feelings.This should always be the correct management of behavioral problems: the "ecological" analysis and the acronym DICE (Describe, Investigate, Create, Evaluate) described by Kales [20] should be the guideline to be followed not only by the caregiver but also by all the nursing team. However, so complex and aggressive symptoms, the confusing diagnoses and the ambiguity, inevitably cause distresses even in strong relationships [21]. Recent studies report that the rate of separation and divorce in the presence of a serious illness of one of the spouses is lower when it is the man to be sick, emphasizing the greater "resilience" of women in providing care to the partner [22]. Susan clashes with the loss of identity of Robin, which only occasionally resurfaces during the fluctuations and, at one point, she seems to become almost an helpless spectator of the disease.

\section{The lack of information}

It is evident that the assistance to the patient becomes much more difficult because of the lack of information and training that caregivers should receive from the health personnel; caregiver NEEDS correct help and support in order to continue his/her existence alongside the loved one who becomes more and more a stranger [23]. Loneliness, confusion, feelings of inadequacy and of loss are the feelings most often expressed by family members, which start their journey of hope among various doctors, groping in the dark, also searching for a better diagnostic definition [24,25].

\section{Awareness of the disease}

Robin was aware and this has certainly increased pain and sufferings. However, the insight is also a powerful tool, if well directed, to the empowerment of the patient and for the doctor-patient relationship. If he had received a diagnosis (and treatment, however modest [26]) it could have been possible to reduce his anxiety. How many patients are convinced of "being wrong, mad or bad" when it is the behavioral disorder of the disease speaking for them. Maybe he would not commit suicide or may be yes....impossible to say. Insight is poorly tolerated by patients and not at all by the family however, the increasing pain linked with the insight sometimes gives to the patient one vital impulse (I am aware of what is happening to me and therefore I suffer but I am still alive). When it turns off with the worsening of the disease, a merciful oblivion and perhaps a greater serenity come.

Full insight is usually present in Alzheimer's patients for a long time [27] and in many other forms of dementia. It is completely absent in patients with frontotemporal dementia-behavioral type [28]. How many times to the classical request: "What is the reason for this visit?" we hear answers like: "What do I know? They have brought me here, I'm fine". Robin, instead, asked the physician to make a more detailed diagnosis; Parkinson's diagnosis did not convince him, "Do I have Alzheimer's? Am I schizophrenic?" He asked, but they reassured him unnecessarily.

\section{The theme of suicide}

The depressive symptoms that occur in DLB are, like the cognitive symptoms, fluctuating, with alternating periods of relative comfort and periods of deep frustration able to cause, especially in the early stages, suicide attempts. This is probably related to the awareness of the disease and to the fear for future. Studies on the issue of suicide in patients with dementia are few, but the risk of suicide appears to be higher immediately after the communication of the diagnosis. This happens especially in young people having insight, who do not have depression, and severe cognitive impairment [29]. However, the risk of suicide remains high even after years from the diagnosis of Alzheimer's disease, highlighting the importance of paying attention to any signal that might suggest a suicidal intention [30]. We reflect on Robin's bewilderment about the impotence and chilling fear of 
becoming like one of the characters in his "Awakening", or even on the possibility of experimenting terrifying hallucinations. However, because of his full awareness we could not exclude that his gesture might be interpreted as a final act of love for Susan, to free her from the burden of the disease.

\section{The importance of neuropathology}

In Susan's letter it strikes her need to know the diagnosis of the disease that took away her husband, this knowledge came only after his death, with the autopsy. Thus, finally, it reveals the origin of all the symptoms of the disease seemingly unrelated to each other. Neuropathology explains how the disruption of amygdala and medial nucleus of the thalamus, not specific but also present in DLB, is responsible for behavioral disorders for the close links with the prefrontal network, unfortunately, without any possibility of objectification [31]. The certitude of the diagnosis of dementia, given by the neuropathological examination, seems to be no longer useful for the family of the affected person [23], nor for the doctor. This misconception has led over the years to neglect almost entirely the neuropathological study and relegate it, exclusively in research settings. Susan's reaction shows us how the diagnosis is important and the awareness of who has been the "demon" can only increase the acceptance of the disease and the loss of one's dear, in addition to the scientific implications that neuropathological diagnosis brings with it [32].

\section{Conclusion}

Today, only the half of patients with any kind of dementia receives diagnosis. The narration of the personal pain of Robin Williams suffering from LBD, through his wife's pen, was the starter point to reflect on the complexity of these diseases. The reflections must be transformed into new attitudes towards dementias. The hope of Susan, and of many family members, is that the suffering of their relatives may one day help other patients, other families and doctors and researchers to fight these terrible diseases. Her commitment in supporting research through the Brain Foundation is, again, a way to sublimate the pain and emptiness of loss. How many Susan we encountered in our clinics, in our associations and at our side in our work of assistance and research, full of hope, pleading and willing to do everything, the ultimate, and the impossible to go on and fight on behalf of their loved ones. With them and for them we will not surrender.

\section{References}

1. Williams SS (2016) The terrorist inside my husband's brain. Neurology 87(13): 1308-1311.

2. Connolly A, Gaehl E, Martin H, Morris J, Purandare N (2011) Underdiagnosis of dementia in primary care: variations in the observed prevalence and comparisons to the expected prevalence. Aging Ment Health 15(8): 978-984.

3. Gramaglia C, Cantello R, Terazzi E, Carecchio M, D’Alfonso S, et al. (2014) Early onset frontotemporal dementia with psychiatric presentation due to the C9ORF72 hexanucleotide repeat expansion: a case report. BMC Neurol 14: 228.
4. Ng AS, Sias AC, Pressman PS, Fong JC, Karydas AM, et al. (2015) Youngonset frontotemporal dementia in a homozygous tau R406W mutation carrier. Ann Clin Transl Neurol 2(12): 1124-1128.

5. Sarazin M, Chauviré V, Gerardin E, Colliot O, Kinkingnéhun S, et al. (2010) The amnestic syndrome of hippocampal type in Alzheimer's disease: an MRI study. J Alzheimers Dis 22(1): 285-294.

6. Frasson P, Ghiretti R, Catricalà E, Pomati S, Marcone A, et al. (2011) Free and Cued Selective Reminding Test: an Italian normative study. Neurol Sci 32(6): 1057-1062.

7. McKhann GM, Knopman DS, Chertkow H, Hyman BT, Jack CR , et al. (2011) The diagnosis of dementia due to Alzheimer's disease: recommendations from the National Institute on Aging-Alzheimer's Association workgroups on diagnostic guidelines for Alzheimer's disease. Alzheimers Dement 7(3): 263-269.

8. Rascovsky K, Hodges JR, Knopman D, Mendez MF, Kramer JH, et al. (2011) Sensitivity of revised diagnostic criteria for the behavioural variant of frontotemporal dementia. Brain 134(9): 2456-2477.

9. McKeith IG, Dickson DW, Lowe J, , Emre M, O’Brien JT, et al. (2005) Diagnosis and management of dementia with Lewy bodies: third report of the DLB Consortium. Neurology 65(12): 1863-1872.

10. Altomari N, Laganà V, Smirne N, Notaro P, Bruni AC, et al. (2017) Prevalence and Occurrence of Behavioral and Psychological Symptoms in Alzheimer's Disease: Difference Between Early and Late Onset Phenotypes. XII Congresso Nazionale SINdem 2017 (Società Italiana Neurologia delle Demenze). Firenze.

11. Zhao QF, Tan L, Wang HF, Jiang T, Tan MS, et al. (2016) The prevalence of neuropsychiatric symptoms in Alzheimer's disease: Systematic review and meta-analysis. J Affect Disord 190: 264-271.

12. Bateman RJ, Xiong C, Benzinger TL, Fagan AM, Goate A, et al. (2012) Clinical and biomarker changes in dominantly inherited Alzheimer's disease. N Engl J Med 367(9): 795-804.

13. Rohrer JD, Nicholas JM, Cash DM, van Swieten J, Dopper E, et al. (2015) Presymptomatic cognitive and neuroanatomical changes in genetic frontotemporal dementia in the Genetic Frontotemporal dementia Initiative (GENFI) study: a cross-sectional analysis. Lancet Neurol 14(3): 253-262.

14. Hogan DB, Fiest KM, Roberts JI, Maxwell CJ, Dykeman J, et al. (2016) The Prevalence and Incidence of Dementia with Lewy Bodies: a Systematic Review. Can J Neurol Sci 43(1): S83-S95.

15. Rockwell E, Choure J, Galasko D, Olichney J, Jeste DV (2000) Psychopathology at initial diagnosis in dementia with Lewy bodies versus Alzheimer disease: comparison of matched groups with autopsy-confirmed diagnoses. Int J Geriatr Psychiatry 15(9): 819-823.

16. Stern Y (2009) Cognitive reserve. Neuropsychologia 47(10): 20152028.

17. Reed BR, Dowling M, Tomaszewski Farias S, Sonnen J, et al. (2011) Cognitive activities during adulthood are more important than education in building reserve. J Int Neuropsychol Soc 17(4): 615-624.

18. Stokes LA, Combes H, Stokes G (2014) Understanding the dementia diagnosis: The impact on the caregiving experience. Dementia (London) 13(1): 59-78.

19. Evans D, Lee E (2014) Impact of dementia on marriage: A qualitative systematic review. Dementia (London) 13(3): 330-349.

20. Kales HC, Gitlin LN, Lyketsos CG (2015) Assessment and management of behavioral and psychological symptoms of dementia. BMJ 350: h369.

21. Merrick K, Camic PM, O'Shaughnessy M (2016) Couples constructing their experiences of dementia: A relational perspective. Dementia (London) 15(1): 34-50. 
22. Glantz MJ, Chamberlain MC, Liu Q, Hsieh CC, Edwards KR, et al. (2009) Gender disparity in the rate of partner abandonment in patients with serious medical illness. Cancer 115(22): 5237-5242.

23. Stokes L, Combes H, Stokes G (2015) The dementia diagnosis: a literature review of information, understanding, and attributions. Psychogeriatrics 15(3): 218-225.

24. van der Lee J, Bakker TJ, Duivenvoorden HJ, Dröes RM (2017) Do determinants of burden and emotional distress in dementia caregivers change over time?. Aging \& Mental Health 21(3): 232-240.

25. deVugt ME, Verhey FR (2013) The impact of early dementia diagnosis and intervention on informal caregivers. Prog Neurobiol 110: 54-62.

26. McKeith IG, Del Ser T, Spano P, Emre M, Wesnes K, et al. (2000) Efficacy of rivastigmine in dementia with Lewy bodies: a randomised, doubleblind, placebo-controlled international study. Lancet 356(9247): 2031-2036.

27. Hornberger M, Yew B, Gilardoni S, Mioshi E, Gleichgerrcht E, et al (2014) Ventromedial-frontopolar prefrontal cortex atrophy correlates with insight loss in frontotemporal dementia and Alzheimer's disease. Hum Brain Mapp 35(2): 616-626.

28. O'keeffe FM, Murray B, Coen RF, Dockree PM, Bellgrove MA, et al. (2007) Loss of insight in frontotemporal dementia, corticobasal degeneration and progressive supranuclear palsy. Brain 130(3): 753-764.

29. Haw C, Harwood D, Hawton K (2009) Dementia and suicidal behavior: a review of the literature. Int Psychogeriatr 21(3): 440-453.

30. Serafini G, Calcagno P, Lester D, Girardi P, Amore M, et al. (2016) Suicide Risk in Alzheimer's Disease: A Systematic Review. Curr Alzheimer Res 13(10): 1083-1099.

31. Golden EC, Graff Radford J, Jones DT, Benarroch EE (2016) Mediodorsal nucleus and its multiple cognitive functions. Neurology 87(20): 21612168.

32. Donaghy PC, McKeith IG (2014) The clinical characteristics of dementia with Lewy bodies and a consideration of prodromal diagnosis. Alzheimers Res Ther 6(4): 46.

\section{Your next submission with Juniper Publishers will reach you the below assets}

- Quality Editorial service

- Swift Peer Review

- Reprints availability

- E-prints Service

- Manuscript Podcast for convenient understanding

- Global attainment for your research

- Manuscript accessibility in different formats

( Pdf, E-pub, Full Text, Audio)

- Unceasing customer service

Track the below URL for one-step submission https://juniperpublishers.com/online-submission.php 